\title{
Perceptions and practices of rural Indian women in contraception, abortion, and sexual health: a cross sectional study
}

\author{
Amenda Ann Davis* \\ Department of Obstetrics and Gynecology, All India Institute of Medical Sciences, New Delhi, India \\ Received: 22 December 2018 \\ Accepted: 05 February 2019

\section{*Correspondence:} \\ Dr. Amenda Ann Davis, \\ E-mail: davis.amenda@gmail.com \\ Copyright: (C) the author(s), publisher and licensee Medip Academy. This is an open-access article distributed under \\ the terms of the Creative Commons Attribution Non-Commercial License, which permits unrestricted non-commercial \\ use, distribution, and reproduction in any medium, provided the original work is properly cited.
}

\begin{abstract}
Background: Maternal mortality is an important target of health care policies, especially in India. While numerical indicators of maternal health improve, this can only be sustained with change in the knowledge, attitudes, and practices of women. Gender empowerment is a neglected aspect of health care policy, and there is a need to assess the perceptions of Indian women, the true torch-bearers of change.

Methods: This was a hospital based cross sectional quasi-quantitative study in a sub-district hospital in the town of Ballabgarh, Haryana, India. Married women attending the outpatient clinic, antenatal clinic, labor ward, and primary health centres in the age group of 20 to 40 years were interviewed using a semi-structured questionnaire with both closed and open-ended questions. Health concerns were concurrently addressed.

Results: Author interviewed 956 women. No form of modern contraception had ever been used by $58.36 \%$ of the women. Intra-uterine contraceptive devices were discontinued by $76.12 \%$ of the women who had used them. Emergency contraception was a concept known to $49.89 \%$ of the women, but fraught with misconceptions. Induced abortions was being used as a form of family planning, with nearly $90 \%$ of the women having taken over-the-counter abortifacients. Women were receptive to contraception, and many expressed an interest in long acting contraceptives other than IUCDs.

Conclusions: This study provides insight into the thinking of Indian women regarding family planning. This may help guide family planning policies.
\end{abstract}

Keywords: Abortion, Contraception, Indian women, IUCD, KAP, Rural sexual perceptions, Sexual health, Vaginal discharge

\section{INTRODUCTION}

The Millennium Development Goal 5 had 2 targets; the first to reduce by three quarters the maternal mortality ratio by 2015 from 1990, and the second to ensure universal access to reproductive health. In 2015, the United Nations estimated MMR worldwide was 216 per 100,00 live births, implicating that maternal mortality fell by $47 \%$ since 1990 . In this new era of Sustainable Development Goals, goal 3 is to ensure healthy lives and promote wellbeing for all, at all ages, with a specific target to reduce the MMR to 70 per 100,000 live births by 2030. India has an estimated population of 1.3 billion, contributing $17.7 \%$ of the world's population, with a fertility rate of $2 .{ }^{1}$ Women bear the brunt of the continuously rising population, with the latest estimate of maternal mortality ratio being 167 per 100,000 live births in 2013. ${ }^{2}$ The single leading cause for maternal deaths globally is haemorrhage, accounting for one third of mortality. ${ }^{3}$ Causes of maternal mortality related to abortion account for $8 \%$ of maternal deaths., ${ }^{2,3}$ Maternal deaths can be traced to a vicious web with interplay of 
multiple factors like early age of marriage, anaemia, poor contraceptive practices and resulting abortions for unwanted pregnancies, less spacing between childbirths, and the suppressed social status of women which leads to malnutrition and poor physical health.

Haryana is a state in Northern India with a population of 26 million, $65 \%$ of which is rural. ${ }^{4}$ The estimated sex ratio was 879 in 2011 , with sex ratio at birth being even lower at 834. ${ }^{4}$ Informal estimates placed the sex ratio at birth above 900 in 2017, for the first time in two decades, an achievement which was attributed by media to the "Beti Bachao, Beti Padhao" (Save the daughter, educate the daughter) campaign and stringent measures by the government to prevent illegal prenatal sonographic sex determination and female foeticide. A historically patriarchal society, Haryana may have achieved numerical goals by allowing women to live, but the question of gender power and autonomy is an issue that is under studied. Self-health awareness, knowledge, and practice of the control that women have over their bodies are indicators of true gender empowerment.

\section{METHODS}

Ballabgarh is a town in the district of Faridabad in the state of Haryana, a part of the National Capital Region. The All India Institute of Medical Sciences, New Delhi, set up a rural health program, the Comprehensive Rural Health Services Project, in Ballabgarh in 1961, under the Department of Community Medicine. A 50 bed subdistrict hospital, this caters to a population of 90,000 across 28 villages with intensive field practice in 2 primary centres and 12 sub-centres.

956 women who visited the health centres were selected for the study, from the outpatient clinic, antenatal clinic, labor ward, and primary health centres. The study was carried out from February to March 2018. Informal verbal consent was taken from the participants. Married women in the age group of 20 to 40 years with at least one child were interviewed using a questionnaire with a combination of closed and open-ended questions. The responses were tabulated and analyzed on Apple Numbers. Tests of heterogeneity for categorical variables was done using Pearson's $\chi 2$. Concurrent counselling was done for the various health concerns of the women.

\section{RESULTS}

\section{Participant demographics}

A total of 956 women in the age group of 20 to 40 with at least 1 child were selected for the study. Most of the women in the study were in the age group of 25-30 years of age, native residents of Haryana, and of Hindu religion (Table 1). The mean age of marriage was 17.9 years with a mode of 19 years, with a minimum of 12 years and 24 years reported. The age of participants when they had their first child birth was a mean of 19.6 years, with a mode of 20 years, indicating that most of women conceived immediately after marriage. For women having 2 or less children, the mean time interval between two childbirths was 2.8 years. In women having 3 or more children, this interval was a mean of 2.2 years. The mean number of children was 2.54 , with a mode of 2 children.

Table 1: Demographic characteristics of participants.

\begin{tabular}{|c|c|c|c|}
\hline \multicolumn{4}{|l|}{ Characteristics } \\
\hline Age (years) & $20-25$ & $25-30$ & $30-40$ \\
\hline & $0.41(4)^{*}$ & $\begin{array}{l}85.04 \\
(813)\end{array}$ & $\begin{array}{l}14.53 \\
(139)\end{array}$ \\
\hline \multirow[t]{2}{*}{ Religion } & Hindu & Muslim & Other \\
\hline & $\begin{array}{l}92.99 \\
(889)\end{array}$ & $7.01(67)$ & 0 \\
\hline \multirow[t]{2}{*}{$\begin{array}{l}\text { Age of marriage } \\
\text { (years) }\end{array}$} & $<18$ & $18-23$ & $>23$ \\
\hline & $\begin{array}{l}36.82 \\
(352)\end{array}$ & $\begin{array}{l}51.15 \\
(489)\end{array}$ & $\begin{array}{l}12.02 \\
(115)\end{array}$ \\
\hline \multirow[t]{2}{*}{ Native state } & Haryana & Bihar & Other \\
\hline & $\begin{array}{l}95.92 \\
(917)\end{array}$ & $3.97(38)$ & (1) \\
\hline \multirow[t]{2}{*}{$\begin{array}{l}\text { Age at first } \\
\text { child birth } \\
\text { (years) }\end{array}$} & $<18$ & $18-23$ & $\begin{array}{l}>23 \\
\text { years }\end{array}$ \\
\hline & $\begin{array}{l}24.79 \\
(237)\end{array}$ & $\begin{array}{l}63.91 \\
(611)\end{array}$ & $\begin{array}{l}11.29 \\
(108)\end{array}$ \\
\hline \multirow[t]{2}{*}{$\begin{array}{l}\text { Number of } \\
\text { living children }\end{array}$} & $1-2$ & $3-4$ & $>4$ \\
\hline & $\begin{array}{l}49.47 \\
(473)\end{array}$ & $\begin{array}{l}37.76 \\
(361)\end{array}$ & $\begin{array}{l}12.76 \\
(122)\end{array}$ \\
\hline
\end{tabular}

*Values indicated in percentage. $(n)=$ absolute number

The women were further differentiated according to interval of last or current pregnancy, with 237 (24.79\%) being antenatal, $115(12.06 \%)$ within 6 weeks of last child birth, and $604(63.17 \%)$ more than 6 weeks postpartum. Of the 719 women who were not pregnant at the time of the study, 556 women considered their family complete and 163 wanted one more child, mostly because they did not have a male child. The mean age at which women considered their family complete was 24.3 years with a mode of 25 years, and the mean number of children these women had was 2.7 with a mode of 3.92 women said they did not want to conceive presently because their last child birth was too recent. This implies that a total of $885(92.57 \%)$ women would require contraception, 556 to prevent further childbirth, 92 for spacing pregnancies, and 237 for post-partum contraception.

\section{Utilisation and perception of modern contraceptive methods}

All of the women $(n=956)$ were questioned about the ever use of various contraceptive methods, the duration of use, and reasons for their discontinuation (Table 2). No form of modern contraception had ever been used by $58.36 \%$ 
of the women. Barrier contraception was found to be the most popular mode. Intra uterine contraceptive devices (Copper T 380A and Multi-load 375A) was tried by 155 women, but $76.12 \%$ of them had it removed within one year due to unacceptable side effects embodied by the popular open response "It did not suit me", which was further elucidated with leading questions. Two women reported conception with IUCD in situ, with one stating that she had conceived twice with it and would not recommend it to other people.
Ormeloxifene had been used by only one woman, but due to non-perfect usage lead to contraception failure. Combined oral contraceptives and injectable depot medroxyprogesterone acetate lead to irregular spotting or amenorrhea which was not acceptable. One the of the women noted, "If I do not bleed openly, it's obvious that the dirty menstrual blood is getting accumulated inside of me and causing weakness and stomach pain." Of note, one woman who had received DMPA conceived despite the injection.

Table 2: Ever use of contraception.

\begin{tabular}{|c|c|c|c|c|c|}
\hline \multirow{3}{*}{$\begin{array}{l}\text { Mode of } \\
\text { contraception } \\
\text { IUCD }\end{array}$} & \multicolumn{4}{|l|}{$\begin{array}{l}\text { No. of users } \\
(n=956) *\end{array}$} & \multirow{3}{*}{$\begin{array}{l}\text { Reasons cited for } \\
\text { discontinuation } \\
\text { - } \quad \text { Excessive menstrual } \\
\text { bleeding (72\%) } \\
\text { - } \quad \text { Abdominal pain }(68 \%) \\
\text { - } \quad \begin{array}{l}\text { Perceived somatic side } \\
\text { effects }(88 \%)\end{array} \\
\text { - } \quad \text { Spacing of pregnancy } \\
\text { complete (32\%) } \\
\text { - } \begin{array}{l}\text { Removed with concurrent } \\
\text { tubal ligation }(6 \%)\end{array}\end{array}$} \\
\hline & $12.92(155)$ & $<6$ months & 6 months to 1 year & $>1$ year & \\
\hline & & 22 & 96 & 37 & \\
\hline \multirow[t]{2}{*}{ DMPA } & $0.20(2)$ & Once & Twice & $\begin{array}{l}\geq 3 \\
\text { times }\end{array}$ & \multirow{2}{*}{$\begin{array}{ll}\text { - } & \text { Irregular menstrual spotting } \\
\text { - } & \text { Amenorrhea } \\
\text { - } & \text { Weight gain }\end{array}$} \\
\hline & & 1 & 1 & 0 & \\
\hline \multirow[t]{2}{*}{$\mathrm{COC}$} & $1.04(10)$ & $<3$ months & 3 to 6 months & $\begin{array}{l}>6 \\
\text { months }\end{array}$ & \multirow{2}{*}{$\begin{array}{l}\text { - Was taking for irregular } \\
\text { menstrual cycles which } \\
\text { became regular } \\
\text { - Break through bleeding } \\
\text { - "Weakness" }\end{array}$} \\
\hline & & 4 & 6 & 0 & \\
\hline \multirow[t]{2}{*}{ Ormeloxifene } & $0.10(1)$ & $<3$ months & 3 to 6 months & $\begin{array}{l}>6 \\
\text { months }\end{array}$ & $\begin{array}{l}\text { - Forgot the weekly dose and } \\
\text { conceived }\end{array}$ \\
\hline & & 0 & $0.10(1)$ & 0 & \\
\hline \multirow[t]{2}{*}{$\begin{array}{l}\text { Barrier } \\
\text { (condom) }\end{array}$} & $18.39(271)$ & $\begin{array}{l}<1 \\
\text { Year/occasionally }\end{array}$ & 1 to 2 years & $>2$ years & - None \\
\hline & & 136 & 40 & 55 & \\
\hline $\begin{array}{l}\text { No modern } \\
\text { contraceptive } \\
\text { use }\end{array}$ & \multicolumn{5}{|l|}{$58.36(558)$} \\
\hline
\end{tabular}

Non-pregnant women who required contraception at the time of the study $(n=648)$ were asked about the current utilisation of contraception (Table 3), which revealed an unmet need for contraception of $82.3 \%$. 32 women in the study had undergone tubal ligation, of which 9 had concurrent removal of IUCD with ligation and 12 had medical termination of pregnancy with ligation.

Most of the women perceived ligation as the ultimate safe guard against pregnancy and said they would get it done in the future, but the reasons for not having it done yet included:
- Young children, less than 5 years, discouraged by health care practitioners and family members due to the apprehension of under-5 child mortality.

- Lack of personal bank account which is a mandate in Haryana (so women can receive ligation incentive money)

- Fear of the procedure due to accounts from others who said it was painful since it was done under conscious sedation

- Lack of permission from husband and mother in law

- Although an outlier response, one patient said two of her sisters in law had died after undergoing ligation. 
IUCD's were frequently viewed as a bridge measure before undergoing ligation. All the women in the study unanimously agreed that vasectomy for their husbands was not an option at all.

Table 3: Current contraceptive coverage.

\begin{tabular}{|l|l|}
\hline Mode of contraception & No. of users $(\mathbf{n}=648) *$ \\
\hline IUCD & $8.48(55)$ \\
\hline DMPA & $0.30(2)$ \\
\hline COC & $0.15(1)$ \\
\hline Ormeloxifene & $0.61(4)$ \\
\hline Barrier (condom) & $6.48(42)$ \\
\hline Tubal ligation & $4.93(32)$ \\
\hline No modern contraceptive use & $82.30(534)$ \\
\hline *Values indicated in percentage. $(\mathrm{n})=$ absolute number \\
\hline
\end{tabular}

DMPA was viewed with caution by most of the women. They reported stories of others they knew who had conceived despite being on the injection, chances of amenorrhea, and difficulty in conceiving after getting off the injection.

\section{Poor acceptability of intra-uterine contraceptive devices}

Copper $\mathrm{T}$ was considered a necessary evil by women who felt they had no other option of contraception available to them (Table 4).

Table 4: Reasons for not choosing IUCD.

\begin{tabular}{|l|l|}
\hline Reasons & $76.04 \%$ \\
\hline Fear of heavy bleeding & $75.94 \%$ \\
\hline Fear of pain & $43.09 \%$ \\
\hline Fear of weight gain & $50.52 \%$ \\
\hline Fear of weakness & $19.03 \%$ \\
\hline Fear of cancer & $25.41 \%$ \\
\hline Fear of perforation & $50.41 \%$ \\
\hline Fear of infection & $26.35 \%$ \\
\hline $\begin{array}{l}\text { Fear of reduced sexual satisfaction of partner/ } \\
\text { self }\end{array}$ & $74.47 \%$ \\
\hline Knows someone with adverse effects & $6.38 \%$ \\
\hline Religious reasons & $62.65 \%$ \\
\hline No permission from family & \\
\hline
\end{tabular}

A number of myths and magnification of the side effects by other users, which are poorly dissipated by health care professionals, result in the poor acceptability. A common notion is that Multi-load 375 resulted in less side effects than Copper T 380A; however, the former is not in government supply and the women are required to purchase them with out-of-pocket expenditure. The average cost of Multi-load is INR 200 to 300, but some women reported buying it at an inflated price of INR 700 to 800 . Religious taboos were reported only by the Muslim women who accounted for $7 \%$ of the study population. The importance of society in determining the success of contraceptive techniques is highlighted here, as $74.47 \%$ of the women felt dictated in their choice by the experiences of others, most commonly including heavy bleeding, abdominal cramping, and conceiving despite the use of Copper T. There was no past ectopic pregnancy in any of the recalled histories. Women were also worried of the possibility of sexual distress.

\section{Emergency contraception}

Women were interviewed in depth about what they perceived as emergency contraception (morning after pill). 477 women $(49.89 \%)$ stated that they were aware of the "medicine taken to prevent pregnancy after intercourse". However, when questioned further, it was realised that $301(37.48 \%)$ of these women believed that the first trimester medical abortion was the same as taking emergency contraceptive pills.

54 women $(5.64 \%)$ said they had used LNG containing emergency contraceptive pill at least once. 6 women said they used it regularly as a form of contraception several times a year. None of the women were aware that copper containing IUCD's could be used as emergency contraception.

\section{Practices related to abortion}

Abortion was not a taboo, with most of the women openly willing to discuss their past history and perceptions. Most of them considered termination of unwanted pregnancies a reflection of their own decisionmaking ability to not have more children. A frequent response was, "My period would get overdue, I would realise immediately that I was pregnant, and got the pills from the chemist. I did not want to have another pregnancy just then."

The independence in choosing to abort was not always the case, however. One woman said, "My husband drinks and eats gutka and does not listen to me. I have 4 children and have undergone abortion 6 times. My husband just gets the medicine from the chemist every time. I do not have enough strength for another pregnancy".

$90.14 \%$ of the women reported having at least one induced abortion, either medical or surgical (Table 5), and $60.4 \%$ were done without consulting a health practitioner. Lactational amenorrhea appeared to be a significant risk factor, with $46.11 \%$ having unwanted pregnancies in this period.

Perhaps due to the well-known illegality of prenatal sex determination, this as a cause for MTP could not be elicited in any of the women. The most common causes were that the previous child was too young, economic problems, or completion of family. Women who had undergone abortions reported that they had side effects like prolonged bleeding, abdominal pain, and weakness, and acknowledged, in general, that it was hazardous to their health, but were of the opinion that it was better than having another child. 
Table 5: Practices related to abortion.

\begin{tabular}{|c|c|c|c|}
\hline \multicolumn{4}{|l|}{ Practices used in abortion } \\
\hline & 1 & 2 & 3 or more \\
\hline No. of induced abortions & $51.35(491)$ & $32.00(306)$ & $6.79(65)$ \\
\hline No. of times abortifacient taken without consulting heath practitioner & $31.58(302)$ & $25.52(244)$ & $3.34(32)$ \\
\hline No. of surgical evacuations & $12.02(115)$ & $6.17(59)$ & $0.41(4)$ \\
\hline No. of times conceived during lactational amenorrhea and underwent abortion & $32.21(308)$ & $12.65(121)$ & $1.25(12)$ \\
\hline Perceived Side Effects of self-medicating abortifacients & $\begin{array}{l}\text { - } \text { Prolong } \\
\text { - } \text { Abdomi } \\
\text { - } \text { Weakne } \\
\text { - Vaginal }\end{array}$ & $\begin{array}{l}\text { menstrual sp } \\
\text { I pain } \\
\text { scharge }\end{array}$ & tting \\
\hline
\end{tabular}

\section{Sexual health}

The frequency of sexual intercourse which women reported was variable. A certain risk category, namely, women who lived in different cities from their husbands and did not perceive the need for contraception, accounted for $14.8 \%$ of the study group. Vaginal discharge which was perceived to be abnormal was reported by $74.48 \%$ of the women (Figure 1), and was often associated with symptoms like abdominal pain, dizziness, back pain, fatigue, and weakness. $61.5 \%$ of the women said they had sought treatment for this set of symptoms more than once.

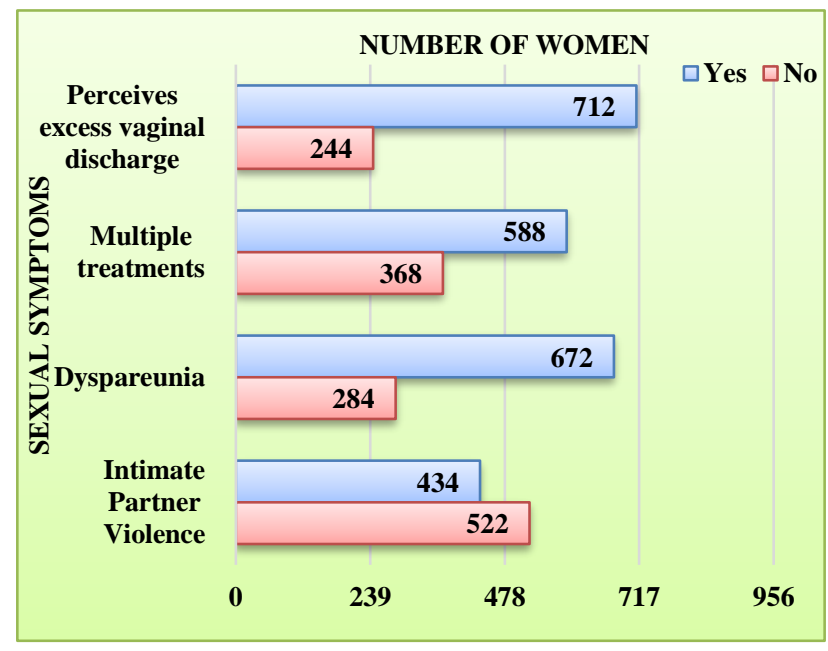

Figure 1: Sexual health perceptions.

Intimate partner violence was reported by $54.6 \%$, in the form of physical abuse and lack of autonomy in choosing not to have intercourse. The response was usually subtle, with the women stating to the effect, "My husband does not agree when I tell him no".

\section{Counselling for contraception}

The women were well receptive to counselling for various modes of contraception (Figure 2). Overall, tubal ligation was the mode of contraception that most of the women expressed they would avail. Many expressed an interest for a "5-year injection" for contraception, which is currently not available in India. Only $2 \%$ refused any of the methods offered to them.

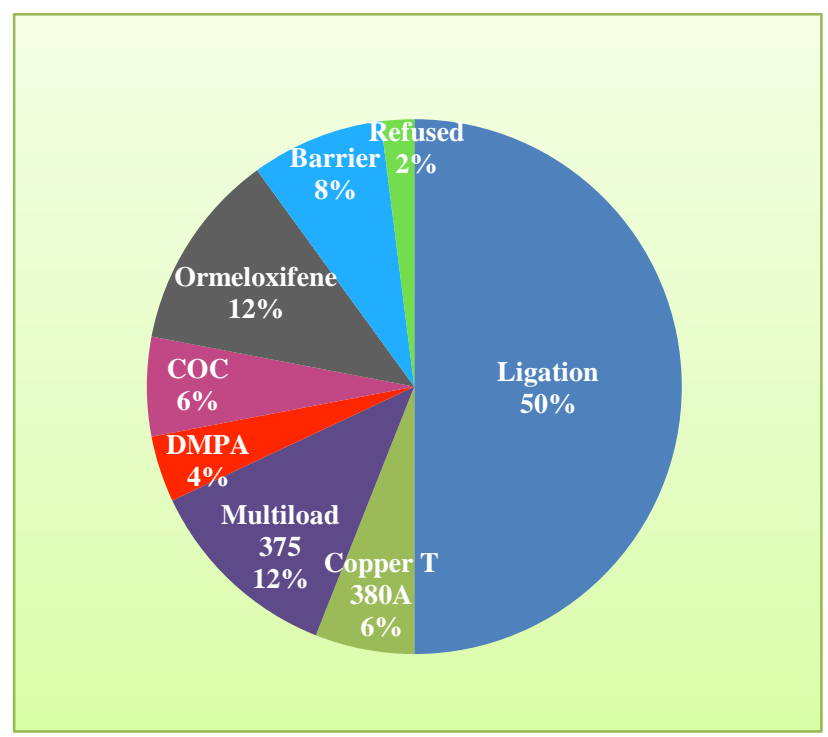

Figure 2: Preferred mode of contraception after counselling.

Sub-group analysis revealed the following (Table 6):

- Women with parity more than 3 were more likely to want ligation.

- Antenatal women and those within 6 weeks postpartum tended to prefer ormeloxifene than other women after counselling about the risks of lactational amenorrhea.

- Women with perceived sexual problems in the form of abnormal vaginal discharge, dyspareunia, history of multiple treatment for reproductive tract infection, or intimate partner violence did not have a significantly different non-preference for IUCD.

- Women with history of IUCD in the past with early removal (in less than a year) due to side effects like 
heavy bleeding and pain were significantly more likely to prefer oral contraceptive pill.
- Women with history of 2 or more abortions were more likely to want long acting contraception in the form of either IUCD or ligation.

Table 6: Differential preferences in contraceptive methods in sub-groups.

\begin{tabular}{|c|c|c|c|}
\hline & Parity $>/-3$ & Parity $<3$ & p-value \\
\hline Wants ligation & 254 & 54 & \multirow{2}{*}{$\mathrm{p}<0.0001$} \\
\hline \multirow[t]{2}{*}{ Does not want ligation } & 230 & 418 & \\
\hline & $\begin{array}{l}\text { Antenatal or within } 6 \text { weeks } \\
\text { post-partum }\end{array}$ & Others & \\
\hline Prefers Ormeloxifene & 88 & 26 & $\mathrm{p}<0.0001$ \\
\hline \multirow[t]{2}{*}{ Does not prefer Ormeloxifene } & 264 & 578 & \\
\hline & Perceived sexual problems & No perceived sexual problems & \\
\hline Does not prefer Copper $\mathrm{T}$ & 580 & 204 & $\mathrm{p}=0.01$ \\
\hline \multirow[t]{2}{*}{ Prefers Copper T } & 112 & 60 & \\
\hline & $\begin{array}{l}\text { History of IUCD removed in } \\
\text { less than } 1 \text { year }\end{array}$ & No history of IUCD intolerance & \\
\hline Prefers COC & 36 & 21 & $\mathrm{p}<0.0001$ \\
\hline \multirow[t]{2}{*}{ Does not prefer COC } & 82 & 817 & \\
\hline & History of 2 or more abortions & No abortions or $<2$ abortions & \\
\hline Wants Copper T or Ligation & 342 & 308 & $\mathrm{p}<0.0001$ \\
\hline Does not want long acting contraception & 29 & 277 & \\
\hline
\end{tabular}

\section{DISCUSSION}

According to the Annual Family Planning Report, 201516, Haryana has a total fertility rate of 2.3 , with $5.9 \%$ of girls married below the age of 18. ${ }^{5}$ The spacing between births was more than the recommended 3 years in $37.4 \%$ women, and the estimated unmet need for family planning was $30.4 \%$, compared to the $80 \%$ estimated in this study. Moreover, the high percentage of abortions underwent without consulting a health practitioner may reflect an even higher need for contraceptive coverage due to unaccounted numbers. These differences may reflect the bias inherent in interviewing women who come to the outpatient clinic to seek health care services; there may be a degree of selection as well as recall bias.

The family planning programme should focus on differential counselling for various methods based on their circumstances. The dominance of sterilization is reiterated and concurs with other studies. ${ }^{6}$ The relevance of timeline in a woman's obstetric history, irrespective of social restrictions, is highlighted in this study. Generally, the contraceptive prevalence has been found to be low in women with only one child $(<25 \%)$ and highest in Hindu households with at least 2 children, indicating that women opt to complete their family soon with little spacing and then choose terminal methods. ${ }^{7}$

Ormeloxifene, a selective estrogen receptor modifier, is being marketed as part of the National Family Planning Programme as Chhaya. The weekly dosage of this pill appeals to many women, particularly immediately postpartum women who want an alternative to IUCD. Since compliance appears to be the chief concern, it is suggested by the author that the accredited social health activist (ASHA) could be dealt with the responsibility of ensuring the weekly dosage on fixed days through home delivery of the pills. The National Heath Mission, in 2011, stated that home delivery of contraceptives would be part of the programme in high focus states, of which Haryana is one. ${ }^{5}$ The only reversible methods of family planning immediately post-partum are ormeloxifene, IUCD, and progesterone only pills. Cerazette is a progesterone only pill which is available in India, at an average cost of INR 375; and hence not an economically feasible option for most. Depot medroxyprogesterone has been classified as category 3 in women immediately post-partum in the WHO Medical Eligibility Criteria and was not promoted for post-partum contraception. ${ }^{8}$ Women who receive counselling during the antenatal and post-partum period are 1.85 and 2.32 times more likely to avail of post-partum contraception and should be the focus of counselling programmes. ${ }^{9}$ There is a lack of awareness on the risk of conception during lactational amenorrhea. Less than $10 \%$ women in a study in Bihar were aware of the return to fertility as early as 6 weeks post-partum, with most considering that resumption of menstruation was the surest sign. ${ }^{10}$ Moreover, the criteria required to fulfil lactational amenorrhea, namely exclusive and frequent breast-feeding including night feeding, are not well known and poorly translated into practice. ${ }^{11}$ The immediate post-partum is a significant 
risk period for unwanted pregnancy, and lactational amenorrhea as a traditional method is inadequate to provide contraceptive coverage. Immediate post abortion long acing contraception appeared to be attractive to women with history of multiple medical abortions and should be promoted. Zavier et al observed that $20 \%$ women in the poorest quintile after undergoing abortion discontinued temporary methods of contraception within 7 months and $40 \%$ by 2 years, with a significantly lower percent of discontinuation following IUCD. ${ }^{12}$

The perceived sexual and reproductive health of women plays an important role in the decision for choosing contraception. Most of the women feel they have some abnormality in the form of vaginal discharge, which may or may not be pathological and usually has deeper sociocultural meaning. ${ }^{13}$ Copper $\mathrm{T}$ is generally not well accepted by such women, although the sample size in present study was too small to make any meaningful conclusion. Alternative methods of contraception should be promoted in such women. The perception that Multiload 375 causes less side effects than Copper $\mathrm{T}$ $380 \mathrm{~A}$ is generally not backed by studies, and targeted counselling should be offered for such women who refuse IUCD merely because Copper T 380A is not available in the health care centre. ${ }^{14}$

Emergency contraception could be a potential for reducing the number of first trimester abortions for unwanted pregnancies. It is an over the counter medication in India. Less than one third of Indian women are aware of it and less than $1 \%$ have used it. ${ }^{15}$ Present study showed a large number of women who thought EC was synonymous to first trimester medical abortion, in line with a study by Ghike et. al who found that $11.7 \%$ of women in Maharashtra thought MTP was a form of contraception. ${ }^{16}$ Misconceptions exist amongst gynaecologists who often feel that ECP's used repeatedly lead to long term health complications. At the International Consortium for Medical Abortion, it was observed that ECP's do not cause long term health risks and should be used as often as required by women who do not have access to safe abortion services in order to prevent unwanted pregnancy. ${ }^{17}$

Lactational amenorrhea and focus on spacing methods of birth control should be emphasized, with focus on ormeloxifene, a well-accepted and safe form of contraception. Policy changes could be introduced to promote fixed day distribution of ormeloxifene to increase compliance. Advertisements, television, and radio broadcasts promoting IUCD should also focus on counselling for sexual health. ASHA should also be taught to de-emphasize the fear associated with leukorrhea, while promoting at least one medical checkup for examination and screening pap smear.

Unsafe abortions are largely prevalent despite the legalization and easy availability of government facilities. Policy should focus on restricting the number of undocumented abortions (pharmacy provided) so these women present to health care facilities for post abortion care as well. While abortifacients are not legally over the counter, they can be easily procured at a higher than usual cost.

Emergency contraception has huge potential for reducing the number of abortions for unwanted pregnancy; studies need to be done on the long-term effects of their repeated use, so they can be freely promoted in women who have difficulties with regular forms of modern contraception.

Women expressed interest in a long acting injectable form of contraception. Subcutaneous implants could be introduced as a part of the program at subsidised rates for women who want LARC but not an intra uterine device.

While the study population is small and not representative of the entire population of Haryana, the results provide valuable insight into the women's preferences and psychology regarding contraception, abortion, and sexual health.

Funding: No funding sources

Conflict of interest: None declared

Ethical approval: The study was approved by the Institutional Ethics Committee

\section{REFERENCES}

1. United Nations, Department of Economic and Social Affairs, Population Division (2017). World Population Prospects: The 2017 Revision.

2. Report of Registrar General of India - Sample Registration System (RGI-SRS) 2011-13.

3. Say L et al. Global causes of maternal death: a WHO systematic analysis. Lancet Glob Health 2014;2(6):e323-33.

4. Census Meta Data, Census of India, 2011.Available at

http://www.censusindia.gov.in/2011census/HLO/Met adata_Census_2011.pdf

5. Family Planning Annual Report 2015-16. Available from:

http://nhm.gov.in/images/pdf/programmes/familyplaning/annual-report/annual-report-fp-division2015-16.pdf

6. De Oliveira IT, Dias JG, Padmadas SS. Dominance of sterilization and alternative choices of contraception in India: An appraisal of the socioeconomic impact. PLoS One. 2014;9(1) e86654.

7. Chaurasia AR, Chaurasia AR, Chaurasia, Ranjan A. Contraceptive Use in India: A Data Mining Approach. Int J Popul Res. 2014;2014:1-11.

8. WHO. Medical Eligibility criteria for Contraceptive Use. 2015;1-276. Available at: www.who.int/reproductive health.

9. Achyut P, Mishra A, Montana L, Sengupta R, Calhoun LM, Nanda P. Integration of family 
planning with maternal health services: An opportunity to increase postpartum modern contraceptive use in urban Uttar Pradesh, India. J Fam Plan Reprod Heal Care. 2016;42(2):107-15.

10. Bhatnagar I, Khan ME, Hazra A. Young Couples in India : How to Meet Their Contraceptive Needs to Space Births ? Data Res Meth. 2013;1-13.

11. Sebastian MP, Khan ME, Kumari K, Idnani R. Increasing postpartum contraception in rural India: Evaluation of a community-based behavior change communication intervention. Int Perspect Sex Reproduct Hea. 2012;38(2):68-77.

12. Zavier AJF, Padmadas SS. Postabortion contraceptive use and method continuation in India. Int J Gynecol Obstet. 2012;118(1):65-70.

13. Trollope-Kumar K. Cultural and biomedical meanings of the complaint of leukorrhea in South Asian women. Trop Med Int Heal. 2001;6(4):260-6.

14. El Beltagy NS, Darwish EA, Kasem MS, Hefila NM. Comparison between Cupper T380 IUD and Multiload 375 IUD in early post-partum insertion. Middle East Fertil Soc J. 2011;16(2):143-8.
15. Dixit A, Khan M, Bhatnagar I. Mainstreaming of emergency contraception pill in India: Challenges and opportunities. Indian $\mathbf{J}$ Community Med. 2015;40(1):49.

16. Ghike S, Joshi S, Bhalerao A, Kawthalkar A. Awareness and Contraception Practices among Women-An Indian Rural Experience. J south asian Fed Obstet Gynaecol. 2010;2(1):19-21.

17. Mittal S. Emergency contraception in India. Presented on 3 May 2011 at the consultation on Mainstreaming ECP in the National Family Welfare Program in Mumbai, India.

Cite this article as: Davis AA. Perceptions and practices of rural Indian women in contraception, abortion, and sexual health: a cross sectional study. Int J Reprod Contracept Obstet Gynecol 2019;8:1022-9. 